\title{
Function and Color: Montana State College Library
}

Miss Heathcote is librarian, Montana State College.

$\mathrm{I}^{\mathrm{N}}$ 1947 the Montana State Legislature had a postwar building fund to divide among the six units of its higher educational system, and the State College was allotted $\$ 400,000$ for the erection of a library building. The library was then housed on the second floor of the administration building in quarters that were dark, dirty, inadequate and thoroughly depressing. Even though the trend of prices at that time made $\$ 400,000$ look pretty small, and growing smaller all the time, the prospect of any kind of building seemed almost too good to be true.

Each time John Paul Jones, the consulting architect from Seattle, brought the plans over to Bozeman, the building was a little smaller. One day the librarian, then Mrs. Lois Payson, remarked to him that he must feel like one of those primitive tribes that shrinks the heads of its victims. "Yes," said he, "and you must feel like the head." Mrs. Payson resigned in June 1947 and the present librarian carried on from there.

It soon became obvious that we did not have the money for a complete building, unless we were willing to accept one that would be inadequate in every way right from the day we moved in. The plans called for an L-shaped, modular type building, the stem of the $L$ to contain the work quarters, staff rooms and most of the stacks, and the foot of the $L$ to be the main reading room. One of the traditions that dies hard, especially with library committees, is the idea of a large, lofty monumental main reading room. Having spent many years of my life in that librarians' nightmare, the University of Washington Library, I was determined against anything even vaguely resembling it. We went round and round on the reading room for awhile but as matters turned out, no decision had to be made at that time. We decided on the stem of the $\mathrm{L}$ only, with the hope that some day Montana would find the money to finish the building.

Ground was broken in September 1948 and in spite of the severe winter which closed down work for over two months, we were able to move in during the Christmas recess of 1949. Nine working days saw the move completed and.we opened up for business in our new quarters on Jan. 9, 1950. As all our furniture had not yet arrived, we made shift with what we had for a while.

The building measures $67^{\prime} \mathrm{I}^{\prime \prime}$ by $132^{\prime} 7^{\prime \prime}$ and has a total area of 8894 square feet. It is built of concrete with brick facing. Its outside more or less matches some of the other architecture on the campus, and is not especially inspiring to look at. We librarians had nothing to say about that and in any case we were more interested in the inside. The building faces north, which is not the best aspect for this climate but so far we have not had trouble. Radiant heating under the front porch would probably have been helpful but we use rubber matting instead to overcome the slipperiness in frosty weather. The cost of the building 
was approximately $\$ 370,000$ or $90 \%$ a cubic foot and the stacks, furniture and equipment cost an additional $\$ 90,000$.

Ours is an open-stack library, but the building arrangement is such that the stacks could easily be closed. We do not contemplate doing this in the foreseeable future, however, for our students need the easy access to books that we now give. Many of them come from communities without libraries and homes without books and we think that their college library should be as open and as easy to use as possible.

In the basement we have the restricted stacks, which are not open to student use, and which contain most of our government documents, the early volumes of our general periodicals and our newspapers. Twenty-eight carrells for the use of graduate students are housed here also. At one end an area is blocked off for storage of our Agricultural Experiment Station publications. A door which is kept locked leads into the lower hall where the machinery room and the public rest rooms are situated. The latter are within a few steps of the front door.

The main floor contains the staff offices, beginning in the northeast corner with the librarian's suite and extending along the east side of the building. The circulation desk is facing you as you enter the front door, and to the right is the general reference area. At the south end are a stack area and a reading room.

The second floor contains a small stack area housing the general books in our special fields, but it is mostly reading room, and the technical reference books in these same fields of engineering, agriculture and home economics are shelved here. In addition there is a small rare book room and two conference rooms which can be made into one by rolling back a folding plastic curtain. One of the rooms does duty as a public typing room also. On this floor there is also a browsing area with easy chairs where bulletin boards and display cases show our wares.

In all parts of the building except the third floor, large, steel-framed windows offer fine views of our beautiful mountains and valley. But the third floor has no windows. It was originally intended for storage purposes only, but when it was decided that we could have only one wing of the building, it was obvious that this area would have to help house our regular collection. A few tables and chairs brought from the old quarters make it possible for students to study up there. In all, we can seat close to 400 of our normal student body of 3000 .

Most of the building is provided with acoustical tile ceilings. The reading room lights are G.E. slimline fluorescents with incandescents used in the stack areas. The floors are covered with $1 / 8^{\prime \prime}$ linoleum in a grey marbled effect with touches of salmon pink in it. Full use has been made of color throughout the building, including coral, .various shades of green, chartreuse, pale lavender and yellow. The furniture is Remington Rand Trend in white oak finished in silver grey and the stacks are grey. The venetian blinds, very necessary in our sunny climate, are silver grey aluminum.

Our Montana students are not in general very much accustomed to libraries, and those that they do know tend to be the Carnegie type building which has long since lost any attractiveness that it might have had. Our task therefore is twofold: to persuade the students to come into the library and to encourage them to read more widely once they have come. Our attractive building and simple arrangement of books are helping greatly to carry out the first task. For the second we are using eye-catching bulletin board displays, and 
special displays of books in the browsing area and on the first floor.

By the time we can build the other wing, library fashions may have changed completely, but nonetheless we have definite ideas as to what should go into it. The original plans called only for a reading room-no basement, no second floor. But now we plan to ask for basement, first floor, second floor and attic, just as we have in the present wing. We believe that we shall require all this space for special reading rooms, map room, rooms for reading machines, individual seminar or conference rooms, a small auditorium for motion picture projection and a room for archives storage. In addition to this wing, provision is made for extension toward the south, and if necessary in the distant future, the building could be completed in a hollow square. The simplicity of the present structure makes it very flexible.

\section{The Administration of Intelligence Archives}

\section{(Continued from page 219)}

constitutes a special problem, for government regulations are demanding. Secondly, an intelligence research center grows rapidly despite careful weeding. Therefore, due consideration for security and growth should govern the allocation of space for the center when it is set up. Poor working conditions, frayed nerves and crowded quarters are not conducive to effective research which requires as much quiet and academic environment as a government building will allow.

In summary then, it may be said that the concept of a research center and intelligence archives is a relatively new extension of library service. It is a testing ground for new techniques of library administration, new machines and new approaches to cataloging and classification. Inventiveness, clear thinking and the ability to work under pressure are particular qualifications needed by people engaged in such professional work. Since no final solution has been found for the multitude of problems presented, an open mind is essential. Most important, an efficient research center demands good organization; a strong administrator in whom is combined a knowledge of librarianship and an appreciation of intelligence service; and a staff alert to new ideas and ready to capitalize on them in improving service, making materials available promptly and facilitating the work of other intelligence workers, thus furthering the mission of U.S. strategic intelligence. 